\title{
This is What Diversity Looks Like*
}

\author{
Making CS Curriculum Culturally Relevant for Spanish-speaking Communities
}

\author{
Joseph Carroll-Miranda $^{\top}$ \\ University of Puerto Rico \\ Río Piedras Campus \\ San Juan, PR \\ joseph.carroll@upr.edu \\ Milagros Bravo \\ University of Puerto Rico \\ Río Piedras Campus \\ San Juan, PR \\ milabravo@gmail.com \\ Gerriann Houser \\ University of Puerto Rico \\ Río Piedras Campus \\ San Juan, PR \\ gerriann.houser@upr.edu \\ Brenda Santiago \\ University of Puerto Rico \\ Río Piedras Campus \\ San Juan, PR \\ brenda.santiago@upr.edu
}

\author{
Patricia Ordonez \\ University of Puerto Rico \\ Río Piedras Campus \\ San Juan, PR \\ patricia.ordonez@upr.edu \\ Michelle Borrero \\ University of Puerto Rico \\ Río Piedras Campus \\ San Juan, PR \\ michelle.borrero@upr.edu \\ Eliud Gerena \\ University of Puerto Rico \\ Río Piedras Campus \\ San Juan, PR \\ eliud.gerena@upr.edu
Agustin Corchado
University of Puerto Rico
Río Piedras Campus
San Juan, PR \\ agustin.corchado1@upr.edu
}

\author{
Edusmildo Orozco \\ University of Puerto Rico \\ Río Piedras Campus \\ San Juan, PR \\ edusmildo.orozco1@upr.edu \\ Luis Lopez \\ University of Puerto Rico \\ Río Piedras Campus \\ San Juan, PR \\ luis.lopez58@upr.edu \\ Dale Reed \\ (moderator) \\ University of Chicago at Illinois \\ Chicago, IL \\ dalereed@gmail.com \\ Andreshka Santana \\ University of Puerto Rico \\ Rio Piedras Campus \\ San Juan, PR \\ andreshka.santana@upr.edu
}

\begin{abstract}
Exploring Computer Science (ECS) [1] spawned from the need to provide access to Computer Science to everyone in the US. The success and commitment to equity and diversity of the ECS curriculum in Latina/o communities inspired an interdisciplinary group of educators from the University of Puerto Rico to tackle the lack of K-12 CSE on the island. This group recognized the need to implode the self-perception of Latinas (os) as being foreign to computing by educating them about Computer Science. Teachers were identified as the catalyst change agents to transform Puerto Ricans students into contributors and creators of technology through computing. The intended audience for this panel consists of practitioners and creators of curriculum looking for creative strategies to engage students from diverse cultural backgrounds in computing using their native language.
\end{abstract}

\section{CCS CONCEPTS}

- Social and professional topics $\rightarrow$ Professional topics $\rightarrow$ Computing education $\rightarrow \mathrm{K}-12$ education $\cdot$ Social and professional topics $\rightarrow$ Professional topics $\rightarrow$ Computing education $\rightarrow$ Model curricula

Permission to make digital or hard copies of part or all of this work for personal or classroom use is granted without fee provided that copies are not made or distributed for profit or commercial advantage and that copies bear this notice and the full citation on the first page. Copyrights for third-party components of this work must be honored. For all other uses, contact the owner/author(s).

SIGCSE '19, February 27-March 2, 2019, Minneapolis, MN, USA

(C) 2019 Copyright is held by the owner/author(s).

ACM ISBN 978-1-4503-5890-3/19/02

https://doi.org/10.1145/3287324.3287339.

\section{KEYWORDS}

ECS; Translation; Culturally Relevant Curriculum; Cultural and Linguistic Equivalence; Professional Development

\section{ACM Reference format:}

Joseph Carroll-Miranda, Patricia Ordo n ez, Edusmildo Orozco, Mila Bravo, Michelle Borrero, Luis Lo pez, Gerriann Houser, Eliud Gerena, Dale Reed, Brenda Santiago, Agustín Corchado, and Andreska Santana. 2019. This is What Diversity Looks Like: Making ECS Culturally Relevant for Spanish-speaking Puerto Ricans. In Proceedings of ACM SIGCSE Symposium (SIGCSE 2019). ACM, Minneapolis, MN, USA, 2 pages.

\section{Summary Topic}

The daunting task of integrating CSE into the high school curriculum requires a system wide coherent vision that harmonizes, across all levels, an effective process of systemic change in education [2]. The first step in accomplishing this task was to find a curriculum that successfully engaged Latino students. After five UPR professors attended ECS-PDs across the US, the need for both a Spanish ECS curriculum and PD was evident. This panel of experts will share the experiences of translating ECS curriculum into Spanish, offering ECS PD in Spanish, implementing the ECS curriculum in the classroom, developing a Research Practitioner Partnership [3], and using a cultural linguistic equivalence model for the validation of the translated ECS curriculum. 


\section{Panel Structure}

Each panelist will be given 10 minutes to present his or her respective positions. Following the presentation, the moderator will facilitate the audience discussion. We anticipate questions about culturally relevant adaptations of the ECS curriculum implementation and how Puerto Rico's cultural and linguistic equivalence model can be applied to other Spanish speaking communities in the U.S.

\section{General Reflections}

As the lead facilitator of both ECS PDs offered in Puerto Rico in Spanish, the moderator will share his experiences. The unique ways in which facilitating this PD stands out include stories of resilience, creativity, musicality and passion. Furthermore, discussion of these cultural differences will help participants develop meaningful culturally relevant experiences with students of diverse backgrounds.

\section{Why Translate ECS Curriculum?}

The cultural differences experienced by a first cohort of educators during ECS PD in the US, made evident the need to have both ECS curriculum and PD available in Spanish. The language barrier became a serious stumbling block not only during the $\mathrm{PD}$, but in the first attempt of implementing the ECS curriculum in PR. The presenter will share how cultural differences impede the effective implementation of ECS curriculum amongst a Spanish-speaking population and emphasize the benefits of having the curriculum in Spanish.

\section{Facilitating a CS PD in Spanish}

ECS PD was offered in Spanish in the summers of 2017 and 2018. As one of the first Spanish-speaking ECS facilitators, the experience of offering this PD allowed for cultural and linguistic adaptations to flourish organically. Several language issues that arose from the ECS translation. The presenter will share some of the most memorable vignettes, share the results of pre- and posttests on both CS content and CS self-efficacy during the second ECS PD in PR.

\section{Lessons from the field}

After the first ECS PD in Spanish in the summer of 2017, a cohort of 10 educators set out to implement ECS in their classrooms. The destructive effects of both Hurricane Irma and Maria combined with administrative obstacles prevented a full implementation of ECS. Nevertheless, this cohort of teachers integrated ECS into their classes. The presenter will share the results of classroom visits using the ECS observation protocols, and share a diverse set of strategies used to teach ECS in Puerto Rico.

\section{The Research Practitioner Partnership Journey}

The community of educators orbiting ECS [4] facilitated the process of creating the first Research Practitioner Partnership (RPP) in Puerto Rico. This RPP (AIPE in Spanish) has been instrumental in the process of validating both the ECS curriculum and PD with respect to cultural linguistic equivalence. The presenter will share how the collaborative and equitable nature of the RPP has created a simultaneous bottom up and top bottom synergy that is catapulting the implementation of a CS curriculum in Puerto Rico.

\section{A Model of cultural linguistic equivalence}

The presenter's vast experience working with the translation of research instruments into Spanish [5] has served as a cornerstone of a cultural linguistic equivalence model for the validation of ECS curriculum's translation. This five phase model for translation and the research driven experiences with this model will be presented to encourage its use in other cultural and linguistic contexts.

\section{REFERENCES}

[1] J. Margolis, J. Goode and J. Flapan, "AA Critical Crossroads for Computer Science for All: 'Identifying Talent' or 'Building Talent,' and What Difference does it Make?. "," in Moving Students of Color from Consumers of Technology to Producers of Technology. Moving Students of Color from Consumers of Technology to Producers of Technology., 2016, pp. 1-23.

[2] J. Kania and M. Kramer, "Collective Impact," Stanford Social Innovation Review, pp. 36-41, Winter 2011.

[3] W. Penuel and D. R. Galagher, Creating Research-Practice in Education, Cambridge, MA: Creating research-practice in education, 2017.

[4] J. Ryoo, J. Goode and J. Margolis, "It takes a village: supporting inquiry- and equity-oriented computer science pedagogy through a professional learning community," 2016.

[5] M. Bravo, "Instrument Development: Cultural Adaptations for Ethnic Minority Research," in Handbook of Racial and Ethnic Minority Psychology, Sage Publications, pp. 220234. 